\title{
Dose-response relationship for chemical carcinogenesis by genotoxic agents
}

\author{
Werner K. Lutz \\ Institute of Toxicology, Swiss Federal Institute of Technology and University of Zurich, \\ Schwerzenbach
}

A cancer cell is characterized by autonomous growth regulation and metastasizing potential. Autonomous growth is thought to be due to defects in the signalling pathway for, and in the control of cell division. These defects are inheritable, so it must be assumed that the DNA of a cancer cell is irreversibly altered in the base sequence and/or gene function or expression. The critical genes are called "oncogenes" if the uncontrolled activity of the gene product confers on the cell the cancerous phenotype. Alternatively, if the presence of the gene product is required for normal growth control, the gene is called a "tumor suppressor gene". In this case, loss of the function can result in malignant transformation. All chemical and physical interactions with DNA entail the possibility to "activate" an oncogene or "inactivate" a tumor suppressor gene. In radiation carcinogenesis, hydroxylation of DNA nucleotides and strand breaks are the predominant mechanisms of genotoxic action. In chemical carcinogenesis, the most important primary lesion is covalent binding of the carcinogen to DNA to form carcinogen-nucleotide adducts. Most wellknown genotoxic carcinogens, such as aflatoxins, polynuclear aromatic hydrocarbons, aromatic amines and nitrosamines, are chemically inert and highly lipophilic. Once in the organism, they have to be metabolized to become excretable. During this process of enzymatic "activation", chemically reactive intermediate metabolites are formed (epoxides, nitronium ions, alkyl diazonium ions). Most of these are inactivated by reaction with uncritical target molecules and only a minute but important fraction ends up in a reaction with DNA.

Testing chemicals for carcinogenic activity involves life-long administration of the test compound to rats and mice and histopathological analysis of about 40 different organs and tissues. Group size in general is 50 animals per dose and sex. The highest dose level is much higher than any human exposure, as an attempt to compensate for the lower number of exposed individuals. As a consequence, the results have to be extrapolated to low dose levels.

In this paper, the biochemical and biological mechanisms which determine the dose-response relationship will be discussed. Conclusions will be drawn for the risk assessment of low-dose exposure of human populations.

\section{Dose-response relationship for genotoxic carcinogens}

\section{DNA adducts as a function of dose}

The processes and reactions which result in DNAcarcinogen adducts include diffusions, enzymatic activation to reactive intermediates, and enzymatic or non-enzymatic reactions of the intermediates with target and non-target molecules. At lowest exposure dose levels, when all concentrations are far below the Michaelis concentrations of the enzymatic reactions, the rate of formation of DNA adducts is expected to be proportional to dose (Fig. 1: top chart; low-dose range). This situation has been found with DNA adducts formed in rat liver after repeated administration of aflatoxin $B_{1}$ in the dose range of $1 \mathrm{ng} / \mathrm{kg}$ to $10 \mu \mathrm{g} / \mathrm{kg}$ body weight per day ${ }^{1}$.
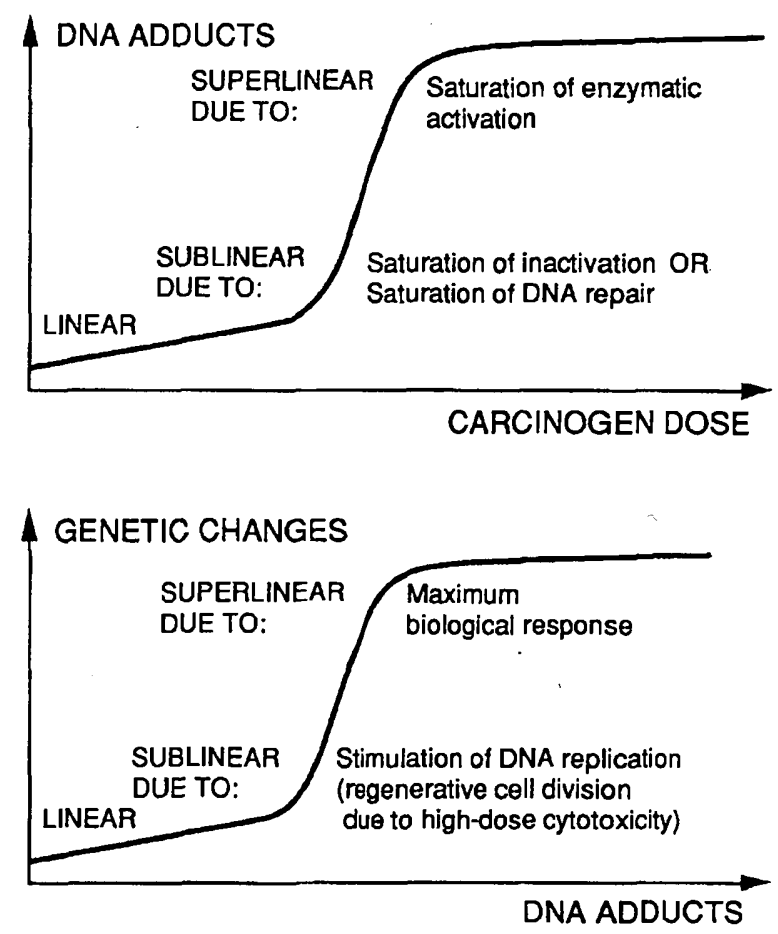

Fig. 1. Schematic illustration of the dose-response relationship for two aspects of the process of carcinogenesis by genotoxic agents. Top chart: Relationship between exposure dose and level of DNA adducts. Bottom chart: Relationship between the primary DNA lesion (DNA adducts) and the number of mutations (genetic changes). 
At intermediate and high dose levels, saturation of enzymatic activities can result in nonlinearities of the dose-response curve ${ }^{2}$. For instance, when the enzymatic inactivation of the reactive intermediate becomes saturated at a given concentration, a further increase of the dose will result in an overproportional rate of DNA-adduct formation. The dose-response curve will be curved upwards (Fig. 1: top chart; sublinearity at intermediate dose range). The sublinearity seen for the formation of DNA-protein crosslinks with increasing doses of formaldehyde has been attributed to the saturation of a glutathione-dependent pathway for formaldehyde detoxication. The same will happen if the DNA repair becomes saturated at higher levels of DNA damage (example: repair of $\mathrm{O}^{6}$-methylguanine formed by methylating agents). Alternatively, if the enzymatic activation is saturated, a flattening-out of the dose-response curve results (Fig. 1: top chart; high dose range). This situation is exemplified with vinyl chloride where both enzymatic epoxidation and tumor induction flatten out above $500 \mathrm{ppm}$ inhalation exposure.

In summary, the dose-response relationship for the formation of DNA-carcinogen adducts is expected to be linear at the lowest exposure levels. At intermediate and high dose levels, however, a number of possibilities exist for the introduction of nonlinearities into the shape of the doseresponse curve. A comparison with radiationinduced DNA damage shows partial analogy: while radiation does not require enzymatic activation to damage DNA or to generate reactive molecules, sublinearities due to a saturation of the inactivation of reactive molecules or of DNA repair are also expected for ionizing radiation.

\section{Mutations as a function of dose}

Formation of DNA-carcinogen adducts is not a sufficient condition for carcinogenesis if the repair is error-free. Only upon DNA replication can a DNA adduct result in a heritable mutation in a daughter strand. The rate of mutations from DNA adducts is therefore dependent on the relative rates of DNA repair and DNA replication.

High dose levels of genotoxic agents are expected to reduce cellular life span because the chemically reactive metabolites of genotoxic carcinogens do not only bind to DNA but also to other cellular components, predominantly protein. Cytotoxicity and necroses, followed by regenerative hyperplasia, represent a condition characterized by an increased rate of cell division. With this shortening of the cell cycle, the time available for DNA repair is reduced so that a larger number of DNA adducts can be fixed as mutations in the daughter cell. This phenomenon will result in a sublinear dose-response relationship (Fig. 1: bottom chart).

According to the rules set by some regulatory agencies, the highest dose level used in a standard rodent bioassay for carcinogenicity has to show signs of general toxicity. In the case of a positive result for tumor induction it is therefore important to investigate whether the target organ for neoplasia was also a target organ for cytotoxicity. If this is the case, reduction of the dose to non-toxic levels might dramatically reduce the risk of induced tumor formation ${ }^{3}$.

\section{Tumors as a consequence of multiple mutations}

Malignant transformation of a normal stem cell requires more than one genetic change. In a twostage situation, the probability of reaching the malignant stage can be approximated by the product of the probabilities of the individual steps ${ }^{4}$. If the mutations derived from DNA adducts accelerate both steps, the overall effect is the product of the dose-response curves for the individual steps. With a linear relationship for each single step, a quadratic dose dependence would result for the entire process.

\section{Conclusions}

The three aspects discussed above illustrate that nonlinear parts in the dose-response relationships are the rule rather than the exception for tumors in a standard animal bioassay for carcinogenicity with maximum tolerated doses of genotoxic carcinogens ${ }^{5}$. For an extrapolation to low dose, therefore, each case must be evaluated for nonlinearities due to i), the steady-state level of DNA adducts, ii), target organ toxicity, iii), the aspect of the multi-stage acceleration of the process of malignant transformation by the carcinogen investigated.

\section{Population heterogeneity: Linearizing the dose-response curve}

In the light of the, aspects discussed above it is astonishing at first glance that only two epidemiological investigations in humans show a deviation from a linear dose-response relationship, i.e. the induction of lung cancer in British physicians by cigarette smoking and the induction of bladder cancer in men occupationally exposed to $\beta$-naphthylamine ${ }^{5}$. In a number of additional epidemiological investigations, nonlinear terms are either not significant, or are based on misleading simplifications in exposure assessment ${ }^{5}$. This lack of higher-order terms in epidemiologial studies has been attributed to a systematic bias 
from the inaccurate measurement of the extent to which target cells are affected ${ }^{6}$. The explanation suggested here is based on the heterogeneity of the human population. It was shown in the preceding section that the frequency of carcinogen-induced mutations is dependent on the steadystate level of promutagenic DNA adducts and the rate of DNA replication. The DNA adduct level itself is dependent on the activity of a number of enzymes involved in the formation and inactivation of reactive intermediates as well as in DNA repair. While the animals used in a standard bioassay for carcinogenicity are homogeneous for these enzymatic activities, the interindividual variation in the human population is enormous ${ }^{7}$. Since the activity of these enzymes is genetically controlled, distinct subpopulations can be discerned which will differ in their susceptibility towards a chemical carcinogen. The following example illustrates the situation.

The hybrid mouse B6C3F1 is often used for animal bioassays on carcinogenicity. It derives from the two inbred strains $\mathrm{C} 57 \mathrm{BL} / 6 \mathrm{~N}$ and $\mathrm{C} 3 \mathrm{H} / \mathrm{HeN}$ and therefore is genetically heterozygous. Let us assume that the gene coding for the enzyme glutathione transferase (GST) is weakly active in the $\mathrm{C} 3$ mice (genotype aa) and highly active in the Black 6 mice (genotype AA). The heterozygous $\mathrm{F} 1$ hybrid will have genotype aA and will exhibit an intermediate enzyme activity. Let us now assume that, in this strain, the dose-response curve for tumor induction exhibits a steep sublinearity in that dose range where the enzymatic inactivation of the epoxide by glutathione transferase becomes saturated, and cytotoxicity and regenerative hyperplasia become tumor-promoting factors (Fig. 2: top chart). If we now outcross the hybrid aA mice inter se, the progeny will show genotypes aa, aA, AA in a ratio $1: 2: 1$, and the different inactivation potential conveyed by the GST activity will result in three subpopulations with different tolerated carcinogen dose levels (Fig. 2: middle chart). If this line of thought is expanded to a larger number of enzymes, and if modulation of the enzyme activities by life-style is allowed, a quasi-linear shape of the dose-response relationship will result (Fig. 2: bottom chart).

\section{Endogenous DNA damage:} Spontaneous tumor formation

It is often assumed that cancer could be prevented if all exogenous genotoxic carcinogens could be eliminated. In contrast to this view is the understanding the DNA is constantly being damaged by endogenous and unavoidable agents and processes ${ }^{8}$. For instance, endogenous electrophiles are found with the co-substrates of physiological transfer reactions (e.g., S-adenosyl-
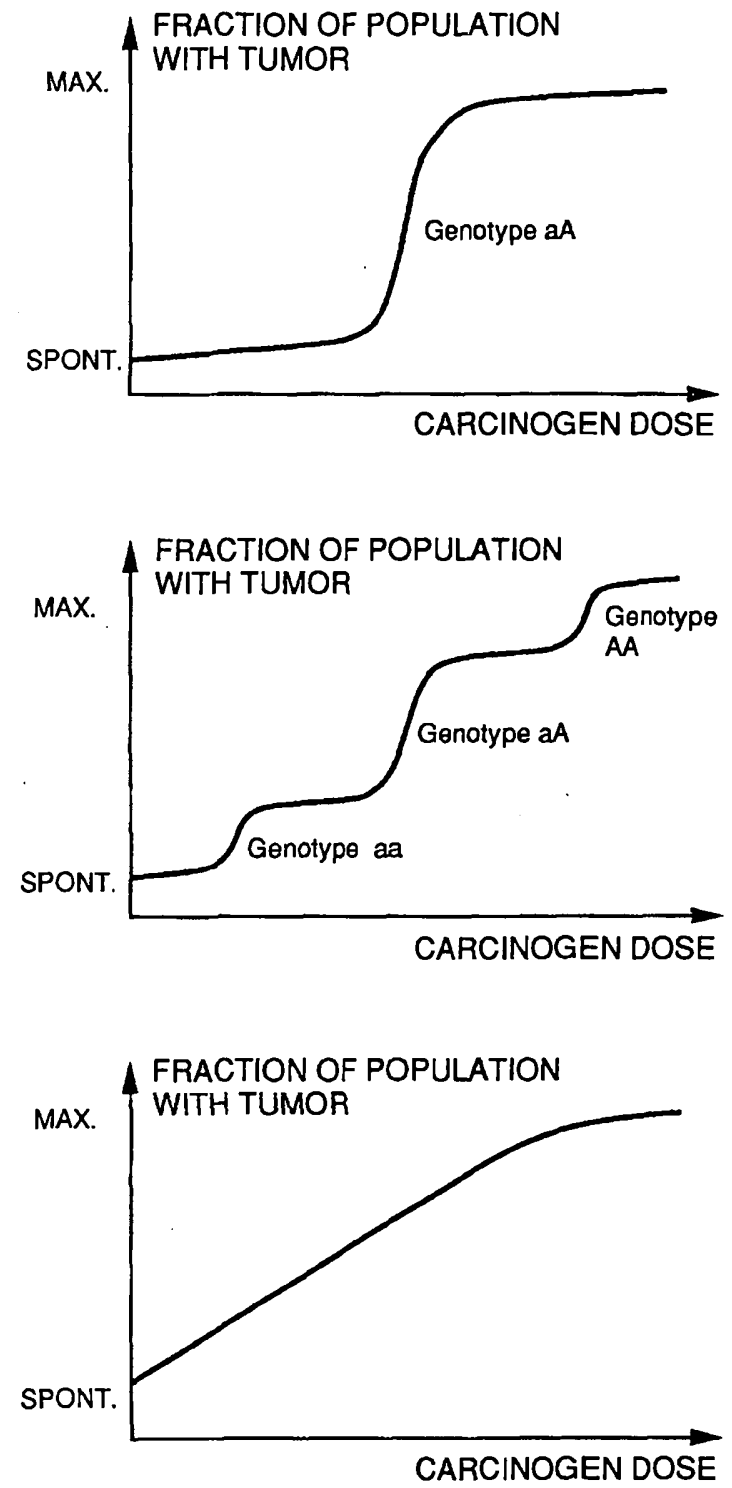

Fig. 2. Cumulative tumor incidence in populations with increasing heterogeneity for enzyme activities critically involved in the formation or persistence of DNA adducts. Top chart: heterozygous situation, typical for a hybrid strain. Middle chart: monogenetic polymorphism. Bottom chart: susceptibility determined by multiple gene loci and modulated by life-style.

methionine for methylations), with aldehyde groups (glyceraldehyde-3-phosphate, formaldehyde, open forms of reducing sugars), or with metabolites of endogenously formed nitroso compounds. Radical-forming reactions : include leakage of the superoxide anion radical from cytochromes and redox cycles, the Fenton reaction which generates hydroxyl radicals from endogenous hydrogen peroxide. DNA instability due to spontaneous deaminations and depurinations as well as errors in DNA replication in the presence of mutagenic metal ions represent a third important class of endogenous genotoxic processes. 
The postulated endogenous genotoxicity could form the mechanistic basis for what is called "spontaneous" tumor incidence. This concept implies that the process of malignant transformation is inevitable. Individuals will show different rates of this process which, in turn, defines the latency period, i.e., the length of the tumor-free life.

\section{Loss of tumor-free life span as a function of dose}

If we assume that all individuals sooner or later develop a tumor spontaneously, the exposure to an exogenous carcinogen "reduces the tumor-free life span". While a low dose is expected to reduce the tumor-free life span only slightly, a large dose would do so dramatically. The dose-effect relationship could be evaluated accordingly.

This approach is exemplified on the basis of the data collected from an experiment with 4320 weanling female $\mathrm{BALB} / \mathrm{c}$ mice treated chronically with $0,30,35,45,60,75,100$, and $150 \mathrm{ppm}$ 2-acetylaminofluorene (AAF) admixed to the $\operatorname{diet}^{9}$. Animals which survived 1,000 days of the experiment were killed. Autopsy and histology of all animals made it possible to attribute a cause to all deaths. The life-shortening effects of specific causes of death were analyzed after adjusting for all competing causes ${ }^{9}$. Figure 3 shows Kaplan-Meier survival curves with respect to death by tumors of various organs. It is obvious that tumors of the liver (top chart of Fig. 3) resulted in an appreciable number of deaths already in the control group. The area shaded horizontally represents 2.6 percent of the rectangle defined by 100 percent of the animals living for 1,000 days. This means that spontaneous liver tumors were responsible for a 2.6 percent reduction of a 1,000-day life span. Treatment of the mice with $100 \mathrm{ppm}$ AAF in the diet now resulted in an additional reduction of the life span by 3.9 percent (vertical shading in the top chart of Fig. 3). Bladder cancer, on the other hand, was practically lacking in the controls but became an important cause of death in the AAF-treated populations (middle chart of Fig. 3). Relative to the tumor situation in the control animals, AAF therefore appears to be a specific carcinogen for the bladder but only an accelerating factor for the growth of spontaneous liver tumors. The effect on reticulum cell tumors (bottom chart of Fig. 3), finally, is so small relative to the high incidence in the control group that AAF is not even said to be carcinogenic for this cell type.

This type of analysis could well be used for doseresponse considerations in that the loss of survival time could be expressed as a function of dose. This would, for instance, mean that the loss of life span due to bladder cancer increases

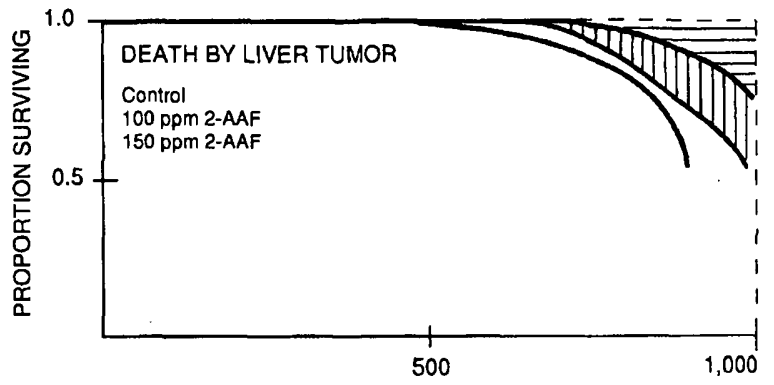

SURVIVAL TIME (DAYS)
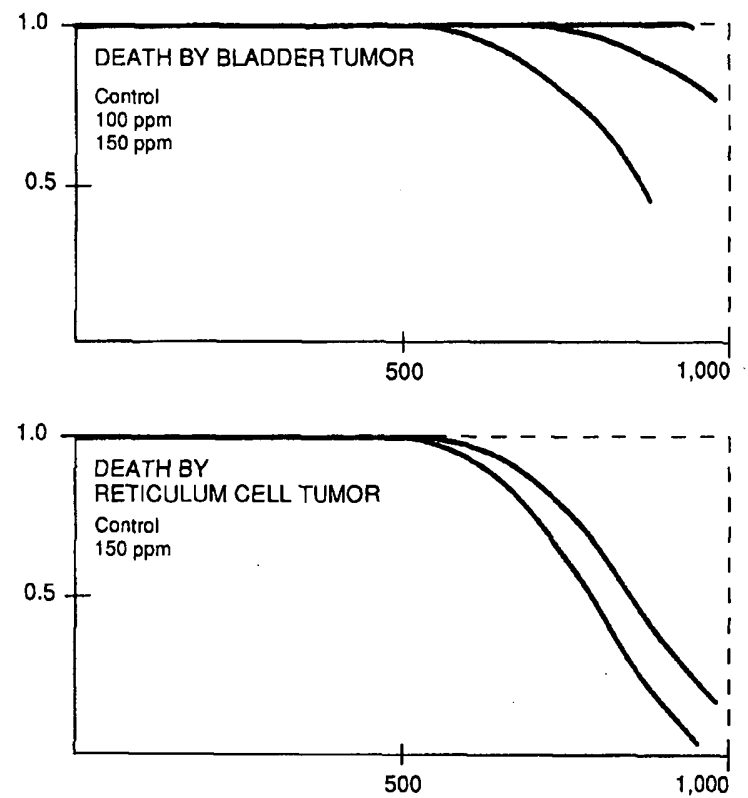

Fig. 3. Kaplan-Meier survival curves with respect to death by various tumors for female $B A L B / c$ mice treated with 2-acetylaminofluorene (AAF) added in the diet. The different curves relate to the different dose levels indicated in the upper left corner. Redrawn from Kodell et al. ${ }^{9}$.

sublinearly when going from 0 to 100 to $150 \mathrm{ppm}$, while a different dose-response relationship is derived for liver tumors. This approach has a number of advantages over the existing analyses:

i) It includes the element of time and ageing, and does not merely reflect the situation at one time-point. In accordance with risk perception, it gives a higher weight to early-appearing tumors as compared with late-appearing ones.

ii) The effect of an exposure to an exogenous carcinogen can be expressed on the basis of the endogenous process leading to spontaneous neoplasia. On this basis, risks of exposure to an exogenous carcinogen do not have to be expressed as absolute values of increased tumor incidence. The compound-related risk can be evaluated relative to an unavoidable risk. 


\section{Comparison with radiation carcinogenesis}

One important difference lies in the fact that rodent bioassays for chemical carcinogenicity are always based upon life-long administration of the test compound, in most cases starting at the age of about 6 weeks. For an extrapolation to low dose levels, therefore, there is no need to introduce a dose- or dose rate-reduction factor as is often required in radiation carcinogenesis to extrapolate from single-dose experiments.

Another difference is based on the requirement of metabolism for most genotoxic carcinogens. Saturation and induction of the enzymes responsible for the activation of the chemical to a reactive species and for inactivation processes can lead to nonlinearities in the dose-response relationship not expected in radiation carcinogenesis.

Similarities are seen, however, with the background radiation and the resulting unavoidable DNA damage as well as with the idea that cell killing at higher radiation dose levels followed by regenerative hyperplasia in the surrounding tissue can result in nonlinearities of the dose-response relationship. The linear-quadratic shape seen in a number of cases might reflect this situation.

\section{Summary}

Formation and repair of DNA adducts from genotoxic carcinogens is expected to be proportional to dose as long as the rates of the enzymatic and non-enzymatic activation and inactivation reactions are all proportional to the substrate concentration. Deviations from linearity are expected in situations of induced and saturated kinetics. A sublinear shape of the dose-response curve is always expected at toxic dose levels when regenerative hyperplasia accelerates the fixation and accumulation of mutations resulting from the DNA adducts. In a heterogeneous population, however, a nonlinear dose-response curve is linearized when genetic and life-style factors result in individual variability in the rates of the activation and inactivation pathways. Finally, in the light of the endogenous and therefore partly unavoidable nature of genetic damage, it is proposed that the cancer risk from exposure to an exogenous carcinogen should be expressed as a reduction of tumor-free life span rather than in absolute terms of additional cases.

\section{Résumé}

Relation dose-réponse des agents génotoxiques dans la cancérogénèse chimique

Le niveau d'adduits des cancérigènes chimiques aux nucléotides de l'ADN est proportionnel à la dose pour autant que les réactions enzymatiques et non enzymatiques ne soient par saturées. A des concentrations plus élevées, il y a de nombreuses possibilités de déviation de la linéarité, surtout en cas de saturation de l'activation des cancérigènes et de la détoxification des métabolites électrophiles. A des doses toxiques, l'induction de tumeurs est accélérée par la division cellulaire stimulée par la régénération du tissu, ce qui peut entraîner une relation exponentielle. Dans une population hétérogène, les nonlinéarités sont linéarisées par les polymorphismes enzymatiques et les niveaux individuels des réactions de toxification et de détoxification. En considérant les atteintes endogènes et inévitables de l'ADN, il est proposé que le risque exogène ne soit plus exprimé en nombre de cas additionnels mais par une réduction du temps de vie sans tumeur.

\section{Zusammenfassung}

Dosis-Wirkungsbeziehung in der chemischen Kanzerogenese durch gentoxische Substanzen

Im tiefsten Dosisbereich ist die DNS-Schädigung durch gentoxische Kanzerogene proportional zur Expositionsdosis, so lange die Geschwindigkeit aller beteiligten enzymatischen und nichtenzymatischen Reaktionen proportional zur Konzentration ist. Wird die Dosis so weit erhöht, dass Enzyme induziert werden und/oder Reaktionen gesättigt ablaufen, ergeben sich vielfältige Möglichkeiten von nichtlinearen Kurvenverläufen. Ein sublinearer Verlauf ergibt sich im höheren Dosisbereich immer dann, wenn Zytotoxizität und regenerative Hyperplasie die Akkumulation von Mutationen beschleunigen. Andererseits wird eine nichtlineare Dosis-Wirkungs-Kurve in heterogenen Populationen geglättet, wenn die kritischen Enzymaktivitäten individuell unterschiedlich sind. Im Extremfall kann eine quasi-lineare DosisWirkungsbeziehung auch bei mechanistisch begründeter Nichtlinearität anzutreffen sein. Wird schliesslich berücksichtigt, dass auch endogene gentoxische Agentien und unvermeidliche Prozesse die DNS schädigen, ist es sinnvoll, exogene Belastungen nur als beschleunigende Faktoren eines spontanen Prozesses anzusehen und die DosisWirkungsbeziehung im Sinne eines Verlustes an tumorfreier Zeit zu analysieren.

\section{References}

1 Buss $P$, Caviezel $M$, Lutz $W K$. Linear dose-response relationship for DNA adducts in rat liver from chronic exposure to aflatoxin B1. Carcinogenesis 1990; 11: 2133-2135.

2 Swenberg $J A$, Richardson $F C$, Boucheron $J A$, Deal $F H$, Belinsky $S A$, Charbonneau $M$, Short BG. High to low dose extrapolation: critical determinants involved in the dose response of carcinogenic substances. Environ Health Perspect 1987; 76: 57-63. 
3 Ames $B N$, Gold $L S$. Chemical carcinogenesis: Too many rodent carcinogens. Proc Natl Acad Sci (USA) 1990; 87: $7772-7776$

4 Moolgavkar SH. Model for human carcinogenesis: action of environmental agents. Environ Health Perspect 1983; 50: 285-291.

5 Zeise L, Wilson $R$, Crouch EAC. Dose-response relationships for carcinogens: a review. Environ Health Perspect 1987; 73: 259-308.

6 Doll $R$, Peto $R$. Cigarette smoking and bronchial carcinoma: dose and time relationships among regular smokers and lifelong nonsmokers. J Epidemiol Commun Health 1978; 32: 303-313.

7 Harris CC. Interindividual variation among humans in carcinogen metabolism, DNA adduct formation and DNA repair. Carcinogenesis 1989; 10: 1563-1566.
8 Lutz WK. Endogenous genotoxic agents and processes as a basis of spontaneous carcinogenesis. Mutat Res 1990; 238: 287-295.

9 Kodell RL, Farmer JH, Littlefield NA, Frith $C H$. Analysis of life-shortening effects in female Balb/c mice fed 2-acetylaminofluorene. In: Staffa JA, Mehlman MA, eds. Innovations in cancer risk assessment (ED01 study). Pathotox Publishers, Park Forest South IL USA 1979; pp 69-87.

Address for correspondence:

Werner K. Lutz

Institute of Toxicology

Swiss Federal Institute of Technology

and University of Zurich

CH-8603 Schwerzenbach/Switzerland 